\title{
USEFUL FIELD OF VIEW IMPAIRMENT IN PARTIAL EPILEPSY
}

\author{
Erik K. St. Louis, Sean McEvoy, Qian Chi Shi, Matthew Rizzo \\ Division of Neuroergonomics and Iowa Comprehensive Epilepsy Program \\ Department of Neurology \\ University of Iowa Hospitals and Clinics and Carver College of Medicine \\ Iowa City, Iowa USA \\ E-mail: erik-stlouis@uiowa.edu
}

\begin{abstract}
Summary: Patients with epilepsy are at elevated risk for automobile crashes. Most collisions in drivers with epilepsy are not seizure-related, but may instead result from cognitive effects of epilepsy and antiepileptic drugs (AEDs) upon driving performance. The Useful Field of View (UFOV) score has demonstrated good sensitivity and specificity for predicting automobile crashes. The goal in this pilot study was to assess impairments in the UFOV in subjects with partial epilepsy. Participants included 20 subjects with partial epilepsy. Neurologically normal control subjects of comparable age also participated. UFOV was assessed in all participants using the Visual Attention Analyzer, Model 3000 (Visual Resources, Inc.). UFOV Task scores were added to calculate a UFOV Total score for each subject. UFOV scores were higher on all UFOV tasks in subjects with partial epilepsy compared to neurologically normal individuals of similar age $(\mathrm{p}<$ 0.05, Wilcoxon Rank Sum Test), suggesting a greater crash risk in individuals with partial epilepsy, even in the absence of an epileptic seizure. Causes of impaired UFOV scores include processing speed reduction, divided and selective attention impairments, and mild postoperative visual field deficits. Our ongoing studies in drivers with epilepsy are aimed at further differentiating potential effects of seizures, antiepileptic drugs, and surgical lesions upon cognitive abilities that are critical to safe automobile driving.
\end{abstract}

\section{INTRODUCTION}

Epilepsy is a common medical disorder characterized by recurrent spontaneous seizures that may impair social function by compromising activities of daily living. More than two million individuals in the United States have epilepsy (Hauser, 1990). One of the main concerns in epilepsy is fitness to drive, which strongly affects a patient's independence and employment opportunities (Reeves, 1997). Patients with ongoing seizures may have legal or medical restrictions on driving privileges, but patients with seizure-free intervals lasting several months or longer may regain driving privileges in many states (Fisher, 1004; Rizzo, 1996).

Drivers with epilepsy have long been a focus of public safety concern due to increased risk for motor vehicle crashes (Hansotia, 1991; 1993; Lings, 2001). Previous studies of driving and epilepsy have largely focused on the risk of seizure occurrence while driving (Andermann, 1988), and complex partial seizures have raised special concerns (Gastaut, 1987). Yet, most crashes by drivers with epilepsy are not seizure-related (Janz, 1967) and may be caused by the effects of other epilepsy-related factors upon driver performance. Safe driving requires the coordinated contribution of several cognitive processes, including attention, perception, memory, and executive function (decision making and implementation) as well as complex coordinated 
motor functions and overall mobility (Rizzo, 1996; 2004; Rizzo and Kellison, 2004). Cognitive impairments heighten crash risk in several neurological and medical disorders (Ball, 1991; Dubinsky, 1991; 1992; Korteling, 1990; Kumar, 1991; Lings, 1992; Nouri, 1997).

Risk factors for increased collision risk in drivers with epilepsy include co-morbid psychiatric disorders and alcohol abuse (Hansotia, 1993). Epilepsy-related factors likely to affect driving performance include cognitive deficits associated with brain lesions causing the patient's epilepsy and the effects of antiepileptic drug effects on visual and cognitive functions that are necessary for safe driving, such as perception, attention, processing speed, decision making, and motor agility (Seppala, 1979; Meador, 1995; 1998). Objective predictors of collision risk would allow for better counseling of drivers with epilepsy.

We hypothesized that drivers with epilepsy have cognitive impairments associated with increased crash risk. The goal of this pilot study was to determine whether attention factors that are critical to safe driving are impaired in drivers with partial epilepsy. In particular, the Useful Field of View (UFOV) provides a quantitative index of divided and spatial attention and visual processing speed, and UFOV impairments predict an elevated crash risk in state records and in simulated collision avoidance scenarios (Ball, 1991; 1993; Owlsey, 1991; Rizzo, 1997; 2001).

\section{OBJECTIVES}

The goal in this pilot study was to assess impairments in the UFOV in subjects with partial epilepsy.

\section{METHODS}

\section{Participants}

Participants included 20 subjects with partial epilepsy, aged 21-61 years (mean=41.5), including 9 men and 11 women. Eighteen had temporal lobe epilepsy; 12 of these had previous anterior temporal lobectomy (ATL) surgery (5 right ATL and 7 left ATL). One participant had a left hemispheric posterior quadrant multilobar cortical dysplasia, and another had non-lesional centro-temporal epilepsy. No subject had hemispatial neglect. Neurologically normal control subjects of comparable age (mean age 39.3, range 24-56 years) also participated.

\section{Technique}

Visual field assessment for each eye was performed using a standardized automated technique (Humphrey Frequency Doubler, C-20-5 test). UFOV was assessed in all participants using the Visual Attention Analyzer, Model 3000 (Visual Resources, Inc.). Briefly, Task 1 measures how fast a subject can identify a single object (the silhouette of a car or truck) presented at central fixation. Task 2, of divided attention, requires the subject to identify the central fixation target while also identifying a peripheral visual target. Task 3, of selective attention, is the same as Task 2 except the peripheral target is surrounded by distracter shapes. Task 4 is a selective attention task like Task 3, but presents a more difficult central task (same/different discrimination). The dependent measure in each task is a threshold score (ms) at which a participant can achieve $75 \%$ correct target identification. Higher scores indicate poorer 
performance. UFOV Task scores were added to calculate a UFOV Total score for Tasks 1-3 (Edwards, 2005), as well as for Tasks 1-4, for each subject.

\section{RESULTS}

Visual field assessment showed that most ATL subjects had evidence of subtle visual field loss (i.e., incongruous homonymous superior quadrantanopia, sparing the macula). There was no significant difference between age in epilepsy subjects and neurologically normal control subjects $(\mathrm{p}=0.8799)$.

UFOV scores were higher on all UFOV tasks in subjects with partial epilepsy $(\mathrm{p}<0.05$, Wilcoxon Rank Sum Test), indicative of impairments of processing speed, divided attention, and selective attention (see Table 1.

\section{Table1. Useful Field of View Scores in Partial Epilepsy and Neurologically Normal Control Subjects}

\begin{tabular}{|c|c|c|c|}
\hline \multirow{4}{*}{$\begin{array}{c}\text { Sample Size } \\
\text { Useful Field of View (msec) }\end{array}$} & \multicolumn{2}{|c|}{ Group } & \multirow[b]{4}{*}{ p-value } \\
\hline & Epilepsy Subjects & Control Subjects & \\
\hline & $\begin{array}{c}20 \\
11 \mathrm{~F}, 9 \mathrm{M}\end{array}$ & $\begin{array}{c}50 \\
25 \mathrm{~F}, 25 \mathrm{M}\end{array}$ & \\
\hline & \multicolumn{2}{|c|}{ Mean (SD) } & \\
\hline UFOV Task 1 & $24.8(36.6)$ & $16.0(0.00)$ & 0.0214 \\
\hline UFOV Task 2 & $55.1(75.4)$ & $24.9(31.7)$ & 0.0008 \\
\hline UFOV Task 3 & $147.1(101.5)$ & $81.3(48.5)$ & 0.0001 \\
\hline UFOV Task 4 & $269.9(96.2)$ & $206.9(76.8)$ & 0.0075 \\
\hline UFOV Total Tasks $1-3$ & $226.9(193.8)$ & $122.2(76.5)$ & $<.0001$ \\
\hline UFOV Total Tasks $1-4$ & $496.8(273.6)$ & $329.1(141.3)$ & 0.0019 \\
\hline
\end{tabular}

SD: Standard Deviation

\section{DISCUSSION}

Attention is of central importance to driving and may be impaired in advancing age and neurological disorders, including focal cerebral lesions (Rizzo, 2001) and especially in Alzheimer's Disease (Owsley, 1991; Rizzo, 2000). Deficits in attention have been clearly associated with driving performance problems (Ball, 1993; Owsley, 1991; Parasuraman, 1991; Rizzo, 1997; 2001). This study shows deficits of attention in the interictal period in drivers with epilepsy.

Individuals with deficits in attention are more likely than normal drivers to commit errors that cause motor vehicle crashes. Attention is a set of mechanisms allowing the mind to focus on a stimulus or objective, while excluding other internal or environmental stimuli (Vecera and Rizzo, 2004). Two alternative mental processes, one "automatic," the other "controlled," allow the ability to switch, sustain, or divide attention (Parasuraman, 1984). Automatic processes are fast, involuntary, and subconscious, and are likely allow drivers to maintain lateral and longitudinal vehicular control during uneventful driving (McClean, 1973; Godthelp, 1984). Defects in 
automatic attention can reflect drowsiness or distraction by an increased mental workload or divided attention (Dingus, 1989). Controlled attention processes are slow and involve conscious decision-making in response to demanding tasks. Driving behaviors that utilize controlled processes include maneuvering through intersections, lane changing in traffic, driving while performing onboard tasks and while checking the vehicle's mirrors or blind spots.

The main forms of attention include: (1) spatial attention, which determines selection of a stimulus based on position in space; (2) object-based attention, which allows stimulus selection by identification of a stimulus; (3) attentional selection in working memory, for selecting items necessary for later recall and memory encoding; and (4) executive attention, where attention facilitates the individual's choice in performance of a task or behavior (Vecera and Rizzo, 2004). Spatial and object-based attention underlie visual search and identification of visual objects, while attentional selection in working memory operates in selective and divided attention tasks, when multiple simultaneous stimuli or distracting or interfering stimuli are presented, as may be commonplace in daily life, especially during driving.

The UFOV task used in this current study provides a quantitative index of divided and spatial attention and visual processing speed that has demonstrated good sensitivity and specificity for predicting automobile crashes. Reduction of attentional field has been found in elderly subjects (Calvanio, 2004; Crabb, 2004; Sekuler, 2000) and reduced UFOV has been correlated with an increased crash frequency (Ball, 1993; Owsley, 1991). Abnormal UFOV has also been found in post-traumatic brain injury, Alzheimer's disease, and Parkinson's disease (Fisk, 2002; Rizzo, 2000; Uc, 2003). UFOV has been validated as a screening tool for road test failure (Myers, 2000) and has been utilized in retraining neurological patients in visuoperceptual driving skills (Mazer, 2001; 2003; Roenker, 2003).

UFOV subtest and total scores were increased in subjects with partial epilepsy compared to neurologically normal individuals of similar age, suggesting a greater crash risk in individuals with partial epilepsy, even in the absence of epileptic seizures. Chronic causes of impaired UFOV scores in drivers with epilepsy include processing speed reduction, divided and selective attention impairments, and mild superior quadrantic deficits due to surgical lesions of the inferior optic radiations running in Meyer's loop. Episodic or transient cognitive impairments may be due to subtle simple or complex partial seizures, or interictal epileptiform discharges (Aldenkamp, 1996; 2004; Brandt, 1984; Fowler, 1987; Kostopoulos, 2001; Provinciali, 1991). Processing speed reduction has also been seen chronically in epilepsy subjects, and may in part be due to differential effects of antiepileptic drugs (Aldenkamp, 1994; Engelberts, 2002).

\section{REFERENCES}

Aldenkamp, A.P., Alpherts, W.C., Diepman, L., van’t Slot, B., Overweg, J., Vermeulen, J. (1994). Cognitive side-effects of phenytoin compared with carbamazepine in patients with localization-related epilepsy. Epilepsy Research 19(1): 37-43.

Aldenkamp, A.P., Overweg, J., Gutter, T., Beun, A.M., Diepman, L., Mulder, O.G. (1996). Effect of epilepsy, seizures, and epileptiform EEG discharges on cognitive function. Acta Neurologica Scandinavia 93(4): 253-9. 
Aldenkamp, A., Arends, J. (2004). The relative influence of epileptic EEG discharges, short nonconvulsive seizures, and type of epilepsy on cognitive function. Epilepsia 45(1): 54-63.

Aldenkamp, A., Arends, J. (2004). Effects of epileptiform EEG discharges on cognitive function: is the concept of "transient cognitive impairment" still valid? Epilepsy and Behavior 5, Suppl 1: S25-34.

Andermann, F., Remillard, G.M., Zifkin, B.G., Trottier, A.G., Drouin, P. (1988). Epilepsy and driving. Canadian Journal of Neurological Sciences 15(4): 371-7.

Ball, K., Owsley, C. (1991). Identifying correlates of accident involvement for the older driver. Human Factors 33: 583-95.

Ball, .K, Owsley, C., Sloane, M.E., Roenker, D.L., Bruni, J.R. (1993). Visual attention problems as a predictor of vehicle crashes in older drivers. Investigative Ophthalmology and Visual Science 34: 3110-3123.

Brandt, J. (1984). Defective stimulus set attention in generalized epilepsy. Brain and Cognition 3(2): $140-51$.

Calvanio, R., Williams, R., Burke, D.T., Mello, J., Lepak, P., Al-Adawi, S., Shah, M.K. (2004). Acquired brain injury, visual attention, and the useful field of view test: a pilot study. Archives of Physical Medicine and Rehabilitation 85(3): 474-8.

Crabb, D.P., Fitzke, F.W., Hitchings, R.A., Viswanathan, A.C. (2004). A practical approach to measuring the visual field component of fitness to drive. British Journal of Ophthalmology 88(9): 1191-6.

Dingus, T.A., Antin, J.F., Hulse, M.C., Wierwille, W.W. (1989). Attentional demand requirements of an automobile moving-map navigation system. Transportation Research 4: 301-315.

Dubinsky, R.M., Gray, C., Husted, D., Busenbark, K., Betere-Overfield, B., Wiltfong, D., Parrish, D., Koller, W.C. (1991). Driving in Parkinson's disease. Neurology 41: 517-520.

Edwards, J.D., Vance, D.E., Wadley, V.G., Cissell, G.M., Roenker, D.L., Ball, K.K. (In press). Reliability and validity of UFOV Scores. Journal of Clinical and Experimental Neuropsychology.

Engelberts, N.H., Klein, M., van der Ploeg, H.M., Heimans, J.J., Jolles, J., Kasteleign-Nolst Trenite, D.G. (2002). Cognition and health-related quality of life in chronic well-controlled patients with partial epilepsy on carbamazepine monotherapy. Epilepsy and Behavior 3(4): 316-21.

Fisher, R.S., Parsonage, M., Beaussart, M., Bladin, P., Masland, R., Sonnen, A.E., Remillard, G. (1994). Epilepsy and driving: an international perspective. Joint Commission on Drivers' Licensing of the International Bureau for Epilepsy and the International League Against Epilepsy. Epilepsia 35(3): 675-84.

Fisk, G.D., Novack, T., Mennemeier, M., Roenker, D. (2002). Useful field of view after traumatic brain injury. Journal of Head Trauma and Rehabilitation 17(1): 16-25.

Fowler, P.C., Richards, H.C., Berent, S., Boll, T.J. (1987). Epilepsy, neuropsychological deficits, and EEG lateralization. Archives of Clinical Neuropsychology 2(1): 81-92. 
Gastaut, J., Zifkiin, B.G. (1987). The risk of automobile accidents with seizures occurring while driving: relation to seizure type. Neurology 37(10): 1613-6.

Godthelp, J.M., Milgram, P., Blaauw, G.J. (1984). The development of a time related measure to describe driving strategy. Human Factors 26: 257-268.

Hansotia, P., Broste, S.K. (1991). The effect of epilepsy or diabetes mellitus on the risk of automobile accidents. New England Journal of Medicine 324(1): 22-6.

Hansotia, P., Broste, S.K. (1993). Epilepsy and traffic safety. Epilepsia 34(5): 852-8.

Hauser, W.A., Jesdorffer, D.C. (1990). Epilepsy: frequency, causes and consequences. New York: Demos Press.

Janz, D. (1967). Uber den Unfallrisiko durch epileptische Anfalle in Strassenverkehr. Nervenarzt 38(2): 67-68.

Korteling, J.E. (1990). Perception-response speed and driving capabilities in brain-damaged and older drivers. Human Factors 32: 95-108.

Kostopoulos, G.K. (2001). Involvement of thalamocortical system in epileptic loss of consciousness. Epilepsia 42, Suppl 3: 13-9.

Kumar, R., Powell, B., Tani, N., Naliboff, B., Metter, E.J. (1991). Perceptual dysfunction in hemiplegia and automobile driving. The Gerentologist 31: 807-910.

Lings, S. (2001). Increased driving accident frequency in Danish patients with epilepsy. Neurology 57(3): 435-9.

Lings, S., Dupont, E. (1992). Driving with Parkinson's disease: a controlled laboratory investigation. Acta Neurologica Scandinavia 86: 33-39.

Mazer, B.L., Sofer, S., Korner-Bitensky, N., Gelinas, I. (2001). Use of the UFOV to evaluate and retrain visual attention skills in clients with stroke: a pilot study. American Journal of Occupational Therapy 55(5): 552-7.

Mazer, B.L., Sofer, S., Korner-Bitensky, N., Gelinas, I., Hanley, J., Wood-Dauphinee, S. (2003). Effectiveness of a visual attention retraining program on the driving performance of clients with stroke. Archives of Physical Medicine and Rehabilitation 84(4): 541-50.

McClean, J.R., Hoffman, E.R. (1973). The effects of restricted preview on driver steering control and performance. Human Factors 15: 421-440.

Meador, K.J., Loring, D.W., Moore, E.E., et al. (1995). Comparative cognitive effects of phenobarbital, phenytoin, and valproate in healthy adults. Neurology 45: 1494-1499.

Meador, K. (1998). Cognitive and behavioral assessments in AED trials. In: French, J., Leppik, I., Dichter, M.A. (Eds.) Antiepileptic Drug Development, Advances in Neurology, Volume 76. Philadelphia: Lippincott-Raven, 231-238.

Myers, R.S., Ball, K.K., Kalina, T.D., Roth, D.L., Goode, K.T. (2000). Relation of useful field of view and other screening tests to on-road driving performance. Perception and Motor Skills 91(1): 279-90.

Nouri, F.M., Tinson, D.J., Lincoln, N.B. (1987). Cognitive ability and driving after stroke. International Disabilities Studies 9: 110-115. 
Owsley, C., Ball, K., Sloane, M.E., Roenker, D.L., Bruni, J.R. (1991). Visual/cognitive correlates of vehicle accidents in older drivers. Psychology and Aging 6: 403-415.

Parasuraman, R. (1984). Varieties of attention. Orlando, Florida: Academic Press.

Parasuraman, R., Nestor, P.G. (1991). Attention and driving skills in aging and Alzheimer's disease. Human Factors 33: 539-557.

Provinciali, L., Signorino, M., Censori, B., Ceravolo, G., Del Pesce, M. (1991). Recognition impairment correlated with short bisychronous epileptic discharges. Epilepsia 32(5): 684-9.

Reeves, A.L., So, E.L., Evans, R.W., Cascino, G.D., Sharbrough, F.W., O’Brien, P.C., Trenerry, M.R. (1997). Factors associated with work outcome after anterior temporal lobectomy for intractable epilepsy. Epilepsia 38(6): 689-95.

Rizzo, M., Dingus, T. (1996). Driving in neurological disease. The Neurologist 2: 140-60.

Rizzo, M., Reinach, S., McGehee, D., et al. (1997). Simulated car crashes and crash predictors in Alzheimer disease. Archives of Neurology 54: 545-551.

Rizzo, M., Anderson, S.W., Dawson, J., Myers, R., Ball, K. (2000). Visual attention impairments in Alzheimer's disease. Neurology 54: 1954-9.

Rizzo, M., McGehee, D.V., Dawson, J.D., Anderson, S.N. (2001). Simulated car crashes at intersections in drivers with Alzheimer's disease. Alzheimer's Disease and Associated Disorders 15(1): 10-20.

Rizzo, M., Akutsu, H., Dawson, J. (2001). Increased attentional blink after focal cerebral lesions. Neurology 57(5): 795-80.

Rizzo, M., Kellison, I.L. (2004). Eyes, brains, and autos. Archives of Ophthalmology 122(4): 641-7.

Rizzo. M. (2004). Safe and unsafe driving. In: Rizzo, M., Eslinger, P.J. (Eds). Principles and Practice of Behavioral Neurology and Neuropsychology. Philadelphia: W.B. Saunders and Co., 208.

Roenker, D.L., Cissell, G.M., Ball, K.K., Wadley, V.G., Edwards, J.D. (2003). Speed-ofprocessing and driving simulator training result in improved driving performance. Human Factors 45(2): 218-33.

Sekuler, A.B., Bennett, P.J., Mamelak, M. (2000). Effects of aging on the useful field of view. Experimental Aging Research 26(2): 103-20.

Seppala, T., Linnoila, M., Mattila, M.J. (1979). Drugs, alcohol, and driving. Drugs 17(5): 389408.

Smith, D.B., Mattson, R.H., Cramer, J.A., et al. (1987). Results of a nationwide Veterans Administration Cooperative Study comparing the efficacy and toxicity of carbamazepine, phenobarbital, phenytoin, and primidone. Epilepsia 28 (suppl. 3): S50-S58.

Uc, E.Y., Dawson, J.D., Rodnitzky, R.L., Smothers, J.L., Rizzo, M. (2003). Reduction in the Useful Field of View in Parkinson s Disease. Annals of Neurology, Supplement 7: S39.

Vecera, S.P., Rizzo, M. (2004). Attention: normal and disordered processes. In: Rizzo, M., Eslinger, P.J., (Eds). Principles and Practice of Behavioral Neurology and Neuropsychology. Philadelphia: Saunders, 223-245. 